\title{
Validation of a deprivation index for public health: a complex exercise illustrated by the Quebec index
}

\section{R. Pampalon, PhD; D. Hamel, MSc; P. Gamache, BSc; A. Simpson, MSc; M. D. Philibert, PhD}

This article has been peer reviewed.

\begin{abstract}
Introduction: Despite the widespread use of deprivation indices in public health, they are rarely explicitly or extensively validated, owing to the complex nature of the exercise.
\end{abstract}

Methods: Based on the proposals of British researchers, we sought to validate Quebec's material and social deprivation index using criteria of validity (content, criterion and construct validity), reliability and responsiveness, as well as other properties relevant to public health (comprehensibility, objectivity and practicality).

Results: We reviewed the international literature on deprivation indices, as well as publications and uses of the Quebec index, to which we added factual data.

Conclusion: Based on the review, it appears that the Quebec index responds favourably to the proposed validation criteria and properties. However, additional validations are required to better identify the contextual factors associated with the index.

Keywords: deprivation, social inequalities in health, index, validity, reliability, Quebec

\section{Introduction}

Deprivation and other area-based socioeconomic indices are used extensively in public health in a number of countries ${ }^{1-18}$ including Canada. ${ }^{19-23}$ Despite their widespread use, they have seldom been explicitly validated, except in a few mainly British studies. ${ }^{7,24-27}$ Validating a deprivation index means verifying whether it adequately reflects the reality being measured. Validation is a complex exercise because the index must respond to a number of criteria and have certain properties that are useful in its field of application (in this case, public health).

The purpose of this study is to subject Quebec's material and social deprivation index $^{23}$ to these validation criteria and properties. The Quebec index was developed at the end of the 1990s and has since been used in Quebec and Canada in various contexts. In this paper, we first describe the index and then present the validation criteria and properties, first with reference to the international literature, then to the Quebec index. Finally, we discuss the nature of the Quebec index and make proposals for additional validations.

\section{Quebec material and social deprivation index}

The Quebec deprivation index was designed to illustrate social inequalities in health and in the use of health services. Its objectives are primarily exploratory and descriptive in nature. It applies to the entire Quebec population, by place of residence.

The design and creation of the index is based on Peter Townsend's ideas on deprivation and the international literature on social determinants of health. The index has two dimensions, material deprivation and social deprivation. The index is also geographical: it is based on the smallest standardized Canadian census unit, composed of one or more blocks of neighbouring houses with a population of 400 to 700 persons. This unit is the enumeration area (EA) for the 1991 and 1996 censuses and the dissemination area (DA) for the 2001 and 2006 censuses. $^{28}$

The Quebec deprivation index is made up of six socioeconomic indicators by EA or DA: the proportion of people 15 years and older with no high school diploma or certificate; the employment:population ratio of people aged 15 years and older; the average income of people aged 15 years and older; the proportion of people aged 15 years and older living alone; the proportion of people aged 15 years and older who are either separated, divorced or widowed; and the proportion of singleparent families. All but the last are adjusted according to the age and sex of the Quebec population.

We extracted two components from these indicators using principal component analysis (PCA): the material component, which is associated with employment, education and income, and the social component, which is associated with marital status, living alone and single-parent families. For each component, the PCA produces a factor score by EA or DA, indicating its relative level of deprivation. Depending on this score, Quebec EAs or DAs are grouped into quintiles (population groups of 20\%) from the most privileged (quintile 1, Q1) to the least (quintile 5, Q5). Thus, it is possible to

\section{Author references:}

Institut national de santé publique du Québec, Québec, Quebec, Canada

Correspondence: Robert Pampalon, Institut national de santé publique du Québec, 945 Wolfe Avenue, Quebec City, QC G1V 5B3; Tel.: 418-650-5115 ext. 5719; Fax: 418-654-3136;

Email: robert.pampalon@inspq.qc.ca 
follow variations in deprivation for each dimension separately (Q1 to Q5) and for both dimensions simultaneously (Q1Q1 to Q5Q5).

\section{The validation of deprivation indices}

Validation of deprivation indices, including the Quebec material and social deprivation index, is based on proposals in the literature $\mathrm{r}^{7,24-27}$ and, more specifically, on work focused on the surveillance and measurement of deprivation and social inequalities in health. ${ }^{24}$ After reviewing the deprivation indices used in the United Kingdom, Carr-Hill and Chalmers-Dixon ${ }^{24}$ suggested using three criteria to evaluate this type of index (validity, reliability and responsiveness) and also suggested considering other properties useful for health policies. While recognizing that the scientific community identify other criteria and properties, ${ }^{29}$ we used the definition proposed by Carr-Hill and Chalmers-Dixon. ${ }^{24}$

We used three approaches to measure the validity of the deprivation indices. These three approaches are usually referred to as content validity, criterion validity and construct validity.

\section{Content validity}

Content validity refers to the agreement between the general concept of deprivation, its main dimensions and the indicators selected to illustrate them: ${ }^{24}$ Are the dimensions and indicators appropriate? Do they represent all the facets of deprivation that the index is attempting to reflect?

The conceptual foundations of the Quebec material and social deprivation index are mainly based on the proposals set forth by Peter Townsend, ${ }^{30}$ for whom deprivation is a "state of observable and demonstrable disadvantage, relative to the local community or the wider society or nation to which an individual, family or group belongs." The author distinguished between two forms of deprivation: material and social. The first, material deprivation, refers to the lack of the normal goods and amenities of modern living in various areas, such as food, housing, the environ- ment and work. The second, social deprivation, which according to Townsend, is more difficult to define, refers to the fragility of social ties. This fragility may occur within the family unit or it may extend to close relationships, friends, confidants, neighbours and others who provide emotional and material support (social support). It can also reflect the difficulties associated with integration and participation in social relationships and other common activities within the local community, such as recreational or educational activities.

This brief definition of deprivation forms the basis for a number of deprivation indices. $^{7,9,20,25,26,31-33}$ The authors of these indices highlighted the relative character of deprivation, its subjective and objective aspects, and its material and social dimensions. The analysis of deprivation can, however, involve more than two dimensions or different fields ${ }^{13}$ and overlap with other concepts, such as poverty, disadvantage, socio-economic status or position, ${ }^{1,6,10,15,16,26}$ marginalization, ${ }^{22}$ or social isolation or fragmentation. ${ }^{34,35}$ In all cases, the concepts beneath these area-based deprivation indices and other socio-economic indicators remain underdeveloped. ${ }^{25-27}$

The area-based scale is, however, a fundamental element of deprivation indicators that distinguishes them from indicators related to individuals, even though they often serve as a substitute or proxy for each other and are sometimes compared. 1,5,11,16,26,27 An area-based indicator reflects a specific reality ${ }^{6,13,36}$ that varies according to the scale considered. ${ }^{36,37}$

\section{Criterion validity}

Criterion validity is used to verify whether the variations in a deprivation index correlate highly with those of an external measurement of deprivation. ${ }^{24}$ Criterion validity is not used extensively because it is commonly accepted that there is no gold or reference standard for deprivation. Nevertheless, certain practices are similar. For example, some authors have compared the area-based variations of different deprivation indices with one another ${ }^{25,27,37}$ or with those of measurements involving individuals, even though they are different realities. ${ }^{1,16,26}$ Moreover, certain authors have compared the area-based variations of a new index to indices already in use, such as Townsend's. ${ }^{6,7,15,16}$

Because there is no standard or reference measure for deprivation, we preferred to discuss the Quebec index in terms of convergence validity, as will be discussed later.

\section{Construct validity}

Construct validity of a deprivation index in the health sector can take on a number of forms. ${ }^{24,29}$ Above all, it aims to determine whether the construction is consistent with the concept of deprivation. Construct validity is also expressed through consistent relationships between the index and other measurements related to the concept of deprivation, on the one hand, and various health measures and the use of health services, on the other. These forms of validity will be more specifically addressed through convergence validity and predictive validity, respectively.

To operationalize his vision of deprivation, Townsend reviewed various indicators used in Great Britain, some from administrative bases and others from health surveys, ${ }^{30}$ and proposed a material deprivation index combining four indicators. $^{24}$ Other authors added a social dimension by creating a separate social deprivation index, ${ }^{26}$ or social isolation index, ${ }^{34}$ combining a number of indicators, all from censuses.

To construct the Quebec index, we took into consideration these indicators and also conducted a literature review on the social environment and social inequalities in health. ${ }^{34,38-41}$ We then selected our indicators on the basis of theoretical and practical criteria: affinity with one of the two forms of deprivation, known link with health, availability at a fine geographical scale in the census ${ }^{28}$ and a limited number of indicators in the composition of the index (parsimony) to simplify comprehension. We selected six indicators through this process. 
The integration of these indicators in the form of an index was not the subject of any explicit hypothesis. The intention was to let the "natural" area-based variations of the indicators express themselves without a priori grouping. For this, we used principal component analysis (PCA), an exploratory synthesis method widely used in the creation of geographically based indices, ${ }^{3,6,7,13,16,18,20,22,32,33}$ while recognizing the relevance of using groups of experts $^{8,19}$ or equally weighted sums ${ }^{5,25,27}$ for the integration of indicators related to certain indices.

The PCA revealed the presence of two components. In the 2006 census, the first component reflected the variations in education, employment and personal income $^{42}$ (see Table 1). The second component reflected the variations in the proportion of individuals who were living alone, separated, divorced, widowed or living in single-parent families. These results are similar to Townsend's proposals concerning the two dimensions (material and social) of deprivation. However, they differ in terms of education, which according to Townsend, is associated with social deprivation. Moreover, these two components do not appear to be very explicit with respect to the forms of deprivation.

Work connecting the two dimensions of the Quebec index with other indicators

TABLE 1

Indicators and components of the index of material and social deprivation, Quebec, 2006

\begin{tabular}{lcc} 
Indicator & \multicolumn{2}{c}{ Component } \\
& Material & Social \\
\hline No high school diploma or certificate $^{\mathrm{a}}$ & -0.85 & +0.04 \\
Employment:population ratio $^{\mathrm{a}}$ & +0.75 & -0.18 \\
Average personal income $^{\mathrm{a}}$ & +0.83 & -0.28 \\
Living alone $^{\mathrm{a}}$ & -0.12 & +0.82 \\
Separated, divorced or widowed $^{\mathrm{a}}$ & -0.12 & +0.85 \\
Single-parent families $^{\text {Explained variance, \% }}$ & -0.21 & +0.68 \\
Cumulated variance, \% & 34 & 33 \\
\hline
\end{tabular}

Source: Canadian Census, 2006.

Note: These values are factor loadings and can be interpreted as coefficients of correlation between indicators and components. The sign (+ or - ) of the indicators on the material dimension should be reversed to be interpreted in terms of deprivation.

a Proportion of people among those aged 15 years and older, adjusted according to the age and sex of the Quebec population.

from censuses by EA or DA makes it possible to clarify these dimensions. ${ }^{43,44}$ For example, social deprivation is closely associated with residential mobility (frequent moves) and the proportion of renters, two indicators used in the construction of social fragmentation and isolation indices. ${ }^{34,35}$ The fact remains that the census is a limited source of data for reporting on the fragility of social networks.

\section{Convergence validity}

It is therefore necessary to compare the index to external measures (not from censuses) that reflect deprivation and its various dimensions. We conducted three exercises of this kind.

We first compared the spatial variations in the deprivation index to those in the proportion of children living with families receiving last-resort financial assistance from the Government of Quebec (see Table 2). Such assistance is given to families whose liquid assets (cash, etc.) are less than a particular amount that corresponds to the size and needs of the family. It is the only source of income the family has to meet its basic needs (e.g. housing and food). Two-thirds of the families receiving this assistance are single-parent families. ${ }^{45}$ Therefore, we expected material and social deprivation to increase with the proportion of children living with families receiving this assis- 
TABLE 2

Percentage of children living in families receiving last-resort financial assistance, by quintile ${ }^{\mathrm{a}}$ of material and social deprivation, Quebec, 2001

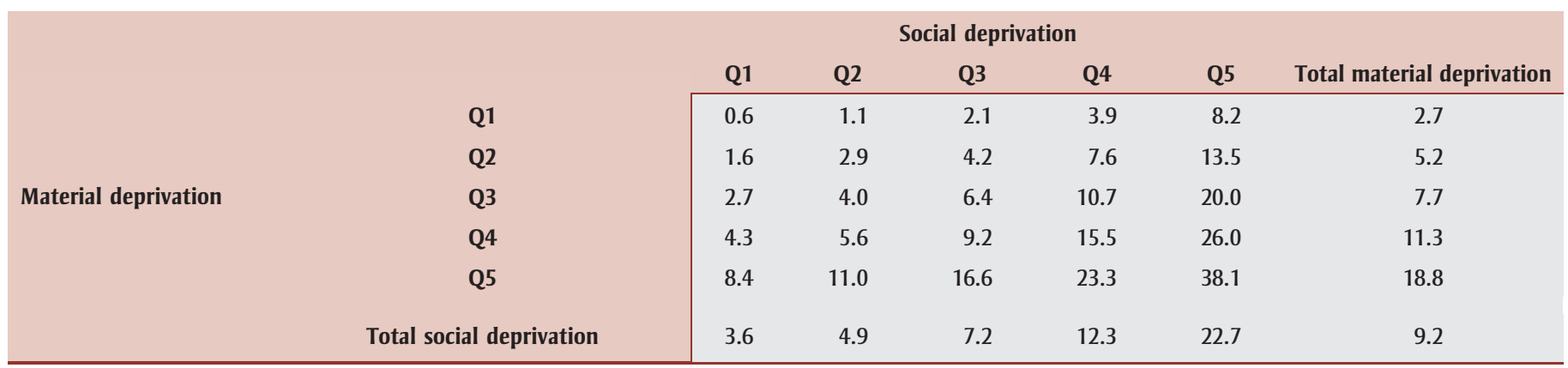

Source: Ministère de l’Emploi et de la Solidarité sociale.

${ }^{\text {a }}$ From Q1, the most privileged quintile, to Q5, the least privileged quintile.

not foster the establishment of roots, neighbourhood ties, or the development or knowledge of and access to local resources and assistance networks, which some associate with social cohesion and social capital. ${ }^{53}$

\section{Predictive validity}

As we have seen, the primary objective of a deprivation index is to identify social inequalities in health and, therefore, the associations between deprivation and health. ${ }^{24}$ These associations must be plausible, corroborate observations made in the literature, or be supported by credible explanations or hypotheses.

Predictive validity is by far the most widely used approach to demonstrate the quality of a deprivation index. ${ }^{24}$ It is seen as "proof" of its performance. For example, links have been made with overall mortality, ${ }^{10,12,14,27}$ premature mortality (0-64 years), ${ }^{4,18}$ cause of death, ${ }^{3,18}$ the incidence of cancer $^{10}$ (including lung cancer ${ }^{14}$ ), long-term disability, ${ }^{25-27}$ perceived health, ${ }^{1,37}$ smoking and nutrition, ${ }^{5}$ low birth-weight, immunization status and lead poisoning among children, ${ }^{11,14}$ sexually transmitted infections, tuberculosis and violence, ${ }^{54}$ myocardial infarction, ${ }^{7}$ hospitalization, ${ }^{14,27}$ and use of medical ${ }^{8}$ and psychiatric services. ${ }^{16}$ Moreover, the strength of the relationship between deprivation and health varies according to the size of the basic spatial unit of the index. The smaller the spatial unit, the stronger the relationship. ${ }^{1,10,11,26,54}$

The Quebec deprivation index accounts for various health and social situations. It is linked to global health indicators, namely, life expectancy and health expectancy at birth and different ages ${ }^{23,44,55,56}$ and mortality, including overall mortality, mortality by medical cause (e.g. cancer, circulatory disease, trauma and stroke), mortality related to lifestyle (e.g. smoking), premature death (less than 75 years), death among young people (18 years or less) and survival. ${ }^{23,55-69}$ For example, an increase in the rate of premature deaths was observed both in the early 1990s and the mid-2000s as a function of material and social deprivation (Figure 1). The same is true for other indicators, such as disability, ${ }^{56,64,70-72}$ the incidence or prevalence of diabetes and high blood pressure, ${ }^{72-74}$ self-reported health, ${ }^{70}$ and protective and risk factors for health: flu vaccination, premature birth or low birth weight, smoking and exposure to secondhand smoke, obesity, food insecurity and physical inactivity. ${ }^{23,61,70,75-78}$ Social issues, such as teenage pregnancy and cases of abuse, neglect and behavioural problems among young people, are also associated with deprivation. . $^{23,44,61}$

Such relationships were also observed in use of health services. An increase in visits to general practitioners was noted with increased deprivation, but an opposing trend was sometimes found for certain medical specialties. ${ }^{44,61}$ This opposing trend was also true for certain free services available for young people aged under 18 years (eye exams) and under 10 years (dental appointments) (Figure 2). However, the use of local community service centres (CLSCs), as well as hospitalization, day surgery and stays in long- term care facilities increased with material and social deprivation. ${ }^{44,61,70,79}$ A recent example is the rate of hospitalization following influenza $\mathrm{A}(\mathrm{H} 1 \mathrm{~N} 1)$ infection (Figure 3).

In summary, the Quebec deprivation index accounts for significant inequalities in health, even though their magnitude may vary depending on the theme under consideration. The two forms of deprivation (material and social) usually act independently. ${ }^{23,44,56-61,63-69,71-76,78,79}$

\section{Reliability}

The reliability of a measurement tool is defined as its ability to produce the same result under the same circumstances. ${ }^{24}$ For deprivation indices, this ability can be expressed through strong correlations between the indicators that form the index. These correlations are often tested using Cronbach's alpha. Some authors refer to an index's internal consistency. ${ }^{6,7,26}$ This internal consistency, however, is not relevant when the index has more than one dimension. ${ }^{24}$ The reliability of a deprivation index can also be expressed through correlation structure stability in time and space. The goal is to verify whether the correlation structure remains, regardless of the period and environment being considered.

The reliability of the Quebec deprivation index can be seen from the perspective of internal coherence for each dimension of deprivation. As seen in Table 1, close correlations exist between the indicators that make up each of the two dimensions 
FIGURE 1

Premature mortality rate by quintile ${ }^{\mathrm{a}}$ of material and social deprivation, Quebec, 1989-1993 and 2004-2008

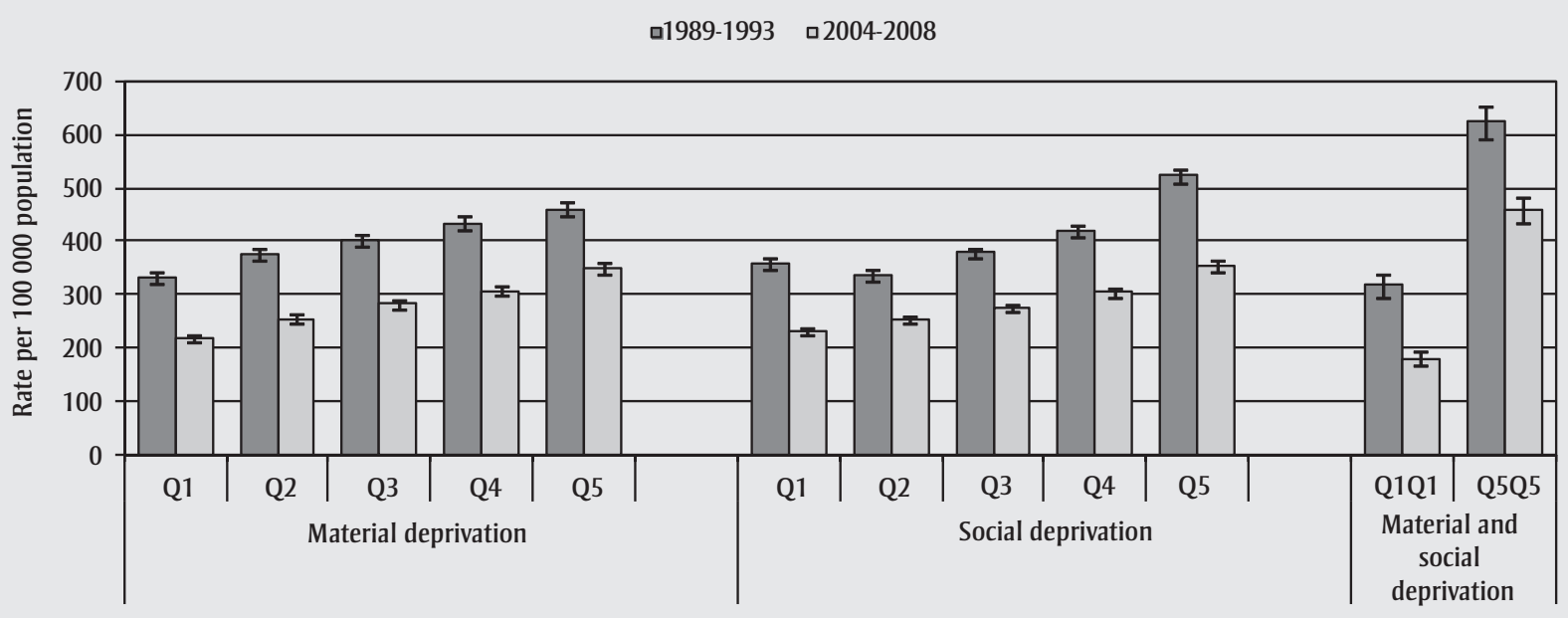

Source: 1991 and 2006 censuses; Quebec death records, 1989-1993 and 2004-2008.

Note: Death rates are adjusted by age, gender, geographical area and other form of deprivation.

${ }^{\mathrm{a}}$ From Q1, the most privileged quintile, to Q5, the least privileged quintile.

FIGURE 2

Percentage of young people aged less than $\mathbf{1 0}$ years who have visited a dentist and of young people aged less than 18 years who have had an eye exam, by quintile ${ }^{\mathrm{a}}$ of material and social deprivation, Quebec, 2000-2002

Dental visit

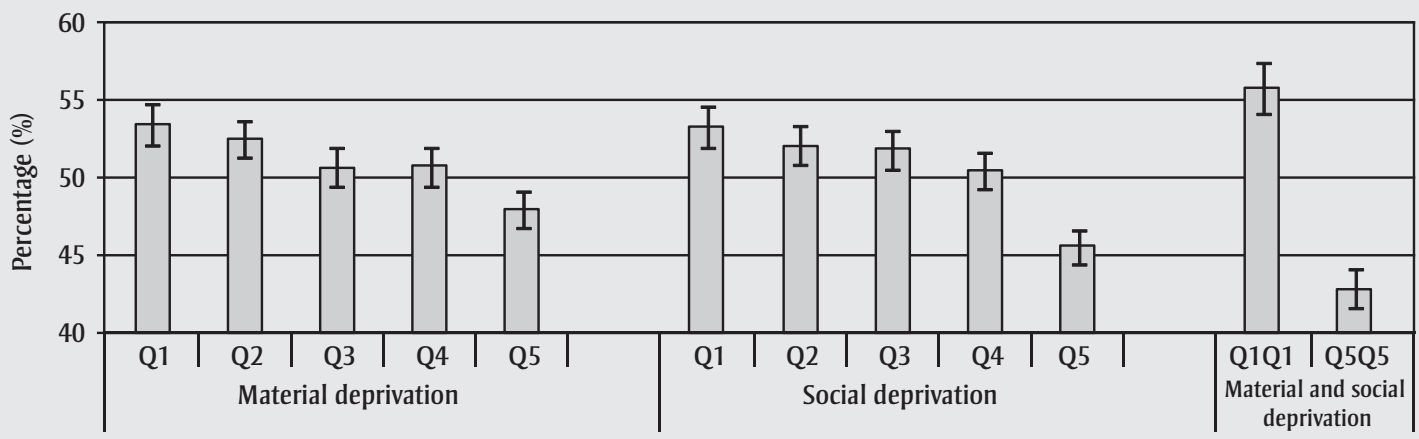

Eye exam

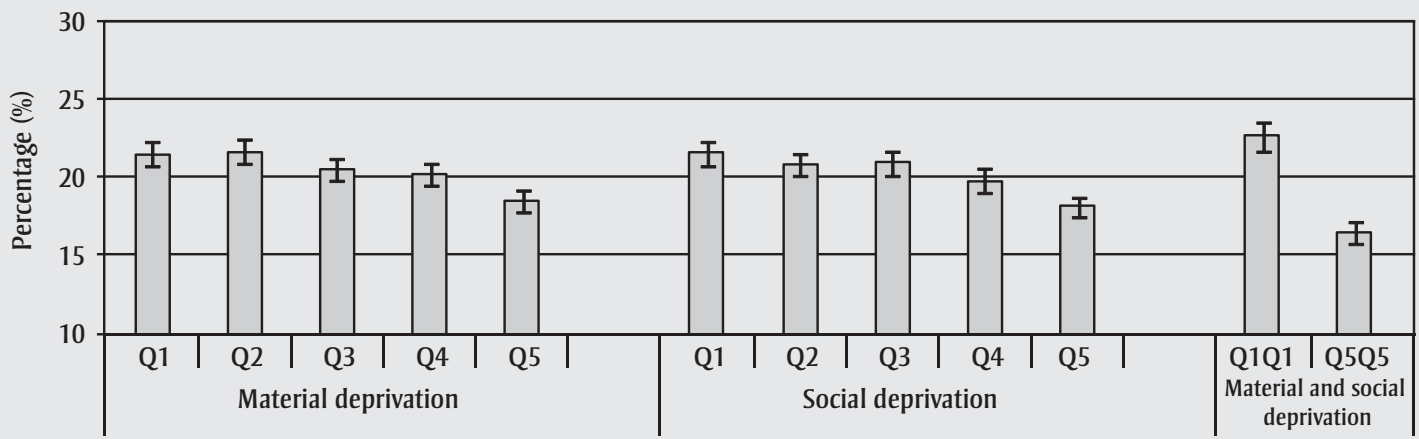

Source: Calculations by the Institut national de santé publique du Québec based on data provided by the Régie de l'assurance maladie du Québec.

${ }^{\text {a }}$ From Q1, the most privileged quintile, to Q5, the least privileged quintile. 
FIGURE 3

Relative risk of hospitalization following an A(H1N1) infection by quintile ${ }^{\text {a }}$ of material and social deprivation, Quebec, April-December 2009

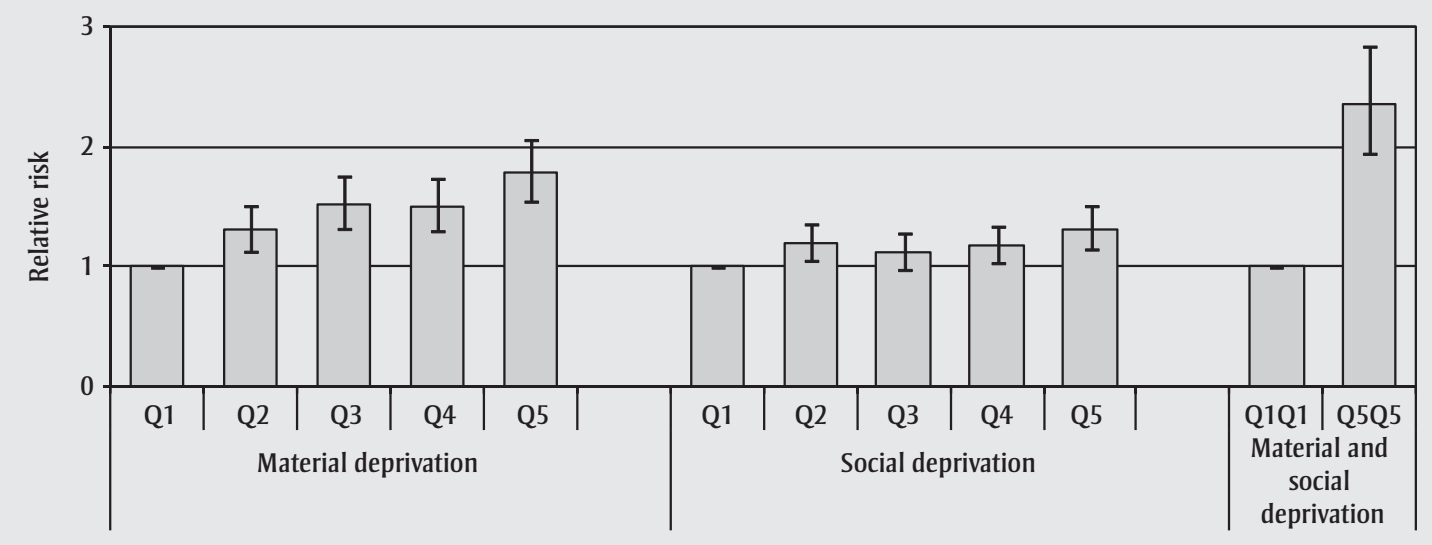

Source: A(H1N1) surveillance record, MED-ÉCHO hospitalization records, Ministère de la santé et des services sociaux du Québec.

Note: The relative risk is adjusted by age, gender, geographical area and other form of deprivation.

${ }^{\text {a }}$ From Q1, the most privileged quintile, to Q5, the least privileged quintile.

(material and social) of the index. This fundamental structure of the index can be seen throughout Quebec and Canada ${ }^{42,68}$ at various levels: regional, census metropolitan areas, cities of varying sizes and rural environments. It is also present for each census year between 1991 and 2006. Although the correlations between the indicators may vary slightly according to the location and period considered, the two-dimensional structure of the Quebec index is maintained. ${ }^{42}$ This fundamental structure seems to be permanent, an essential quality for monitoring the social inequalities in health in time and space.

\section{Responsiveness}

Responsiveness reflects the ability of a measurement tool to detect differences or changes according to the location, time and individual characteristics. ${ }^{24}$ Variations in the deprivation index are observable at the national, regional and local levels, through the use of maps, for example. ${ }^{2,7,8,26,37}$ They are also observable in relation to various health characteristics. The relationships vary according to the age and gender of the population, 3,4,18,27 with adults (aged 25-64 years) usually showing the highest inequalities in health. The inequalities change over the years (reducing or increasing) or with the area $a^{3,4,11,16}$ and fluctuate according to the health issue under study (e.g. cause of death). ${ }^{10,16,27}$
The Quebec deprivation index was used to create an interactive atlas ${ }^{44,80}$ that shows wide variations in deprivation at the provincial level and at a smaller level, in both urban and rural environments. These variations in the Quebec index are also associated with inequalities in health that relate to gender and age, with adults having the highest mortality ratios between groups at the extreme ends of material and social deprivation (Figure 4). Moreover, as is the case elsewhere, ${ }^{18,81-84}$ the Quebec index has identified an increase in relative health differences in Quebec. According to the data presented (Figure 1), the premature mortality ratio between groups at the extreme ends of deprivation increased from 1.8 in 19891993 to 2.4 in 2004-2008. The Quebec index identified health inequalities of varying magnitude according to geographical area and fluctuating over time. ${ }^{62,64,66}$ Thus, inequalities are growing throughout Quebec, except in the Montreal area, where they are actually bigger than in the rest of the province. Such health differences have also been demonstrated elsewhere in Canada. ${ }^{63,67,68}$

\section{Other properties}

In the context of the development of public health policies or programs, deprivation indices must respond to requirements beyond those that are purely technical or statistical. ${ }^{24}$ This is the case for the comprehensibility of the index for an audience made up of decision makers and stakeholders in the field. The index must be easy to understand, appeal to common sense and be conducive to reasonable, unambiguous explanations. Thus, the contribution of the indicators to the index must be precise, clear and, if possible, quantified. The index must also be objective (cannot be manipulated) and be applicable to every part of the area being considered, at the national, regional and local levels. Finally, the index must respond to practical requirements. It must be possible to update it regularly, using the same method, and be manageable in terms of time and cost; it should also be possible to introduce it into health databases.

As we have seen, the Quebec deprivation index remains a simple measure, made up of two components and six indicators that are well known as being connected to health. Its structure is clear, and the weighting of the indicators in the index reflects their correlation with the components (Table 1). Its use demonstrates its comprehensibility for an audience made up of stakeholders and decision makers in the health and social service sectors in Quebec. Local variations in the index corroborated the perception of CLSC stakeholders, ${ }^{79,85}$ and, at a provincial level, 
FIGURE 4

Ratio of death rates between extreme quintiles of material and social deprivation (Q5Q5/Q1Q1) by age group, Quebec, 2000-2004

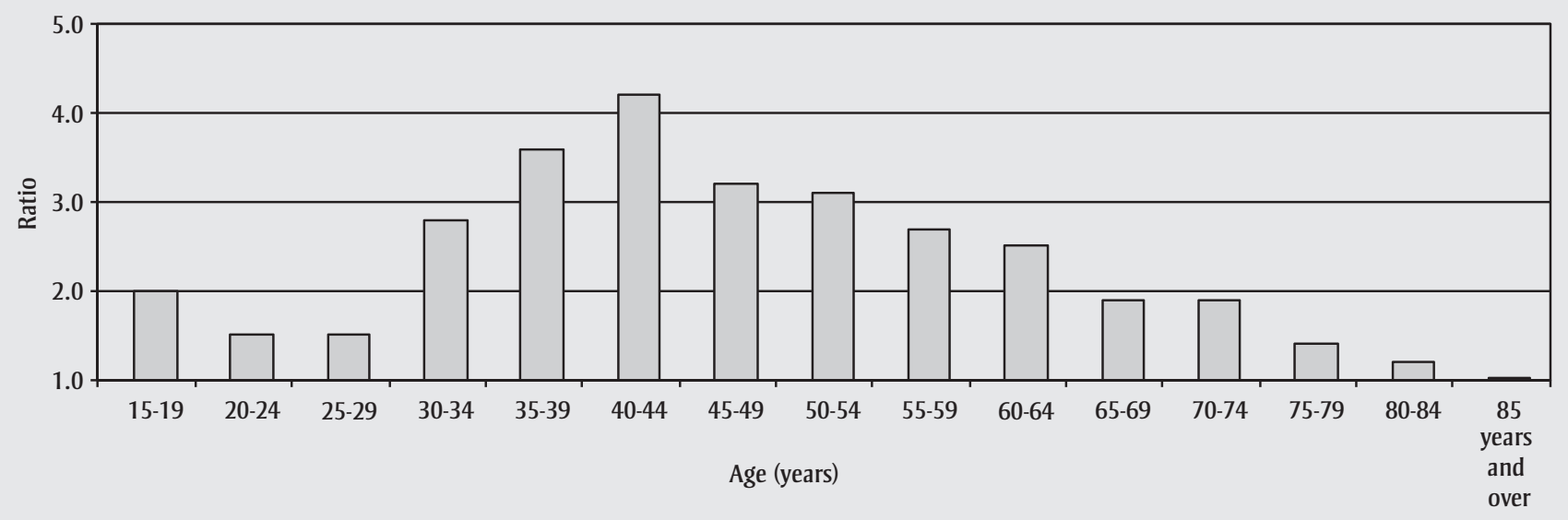

Source: Institut national de santé publique du Québec, 2008; http://www.inspq.qc.ca/Santescope/element.asp?NoEle=740

these variations were used to develop departmental policies ${ }^{61}$ and to allocate health resources among regions. $^{86} \mathrm{~A}$ recent compilation indicates that most of Quebec's regional health and social services agencies use the deprivation index to identify variations in their areas and the connections with various health and social issues. ${ }^{87}$

Although groups of experts were not involved in the design or initial construction of the deprivation index, many health experts (stakeholders and managers) at all geographical levels have since commented on, used and adapted the index to their needs and work contexts, contributing to its validation and evolution. For example, a local version of the index and an interpretation grid of the inequalities in the use of services were developed jointly with local CLSC stakeholders. ${ }^{79,85}$ The grid compares the variations in the index and the knowledge of stakeholders regarding their organization directions and practices (e.g. target clientele, service access criteria), resources available locally (e.g. medical clinics, self-help groups and associations) and hard-to-reach populations (e.g. the homeless or individuals with mental health issues).

Finally, the relevance of the Quebec index depends on its availability over time and space. We have seen that the index exists for 1991, 1996, 2001 and 2006, and that it covers all of Quebec (and Canada) in different versions: national, regional and local. There are supporting products (e.g. interactive maps, population tables, index assignment programs), which are all free and available online. ${ }^{80,88}$ Tables and figures illustrating the health inequalities in Quebec using the deprivation index are regularly produced and posted online. ${ }^{89}$

\section{Conclusion}

Despite the widespread use of deprivation indices, there have been few formal validation exercises. On the basis of the validation criteria proposed by Carr-Hill and Chalmers-Dixon, ${ }^{24}$ it can be concluded that the Quebec material and social deprivation index responds favourably to various requirements for validity, reliability, responsiveness and use in public health.

However, there are limitations related to the geographical nature of the index. The index characterizes the socio-economic attributes of all residents of small areas. Although it is often used as a substitute for measurements related to individuals, the index is a measurement linked to an area. Studies, some of which are from Quebec and Canada, ${ }^{56,64,67,90}$ show that the magnitude of health inequalities is underestimated through geographical measurement, espe- cially in small cities and rural environments. They also reveal that health inequalities are associated with both types of measurements (those related to area and those related to individuals), independently, which signifies that they result from both geographical and individual realities. ${ }^{56,64,67,91-97}$

A better understanding of these geographical realities is therefore necessary to identify all the content and construct elements associated with a deprivation index. To achieve this, a research strategy at the local level combining theories, concepts, methods and indicators is necessary. ${ }^{98-101}$ Reference frameworks on "contextual" factors associated with health must be used..$^{53,98,102,103}$ The social dimension of the index would particularly benefit from being associated with concepts and measurements of social cohesion and capital as well as their components (e.g. values, social support, informal social control and community participation). The material dimension would benefit from being associated with various fields, such as the physical environment (e.g. water and air), the built environment (e.g. housing and access to services), and public (e.g. schools, green space and public transportation) and private (e.g. food stores) infrastructure. This roadmap should be followed for future validation exercises of the Quebec index. 
Finally, it should be noted that this index was designed to illustrate the existence of social health inequalities and that its purposes are exploratory and descriptive. The index is not an explanatory framework for these inequalities. For example, it does not consider dimensions related to health, such as immigration or Aboriginal status, even though these dimensions can be accounted for. ${ }^{63,66}$ Rather, the Quebec index constitutes more of a marker of social and health inequalities and, as a result, is a relevant starting point toward more in-depth studies and increased understanding of these inequalities.

\section{References}

1. Adams J, Ryan V, White M. How accurate are Townsend Deprivation Scores as predictors of self-reported health? A comparison with individual level data. J Public Health (Oxf). 2005;27(1):101-6.

2. Bajekal M, Jan S, Jarman B. The Swedish UPA score: an administrative tool for identification of underprivileged areas. Scand J Soc Med. 1996;24(3):177-84.

3. Benach J, Yasui Y, Borrell C, Pasarin MI, Martinez JM, Daponte A. The public health burden of material deprivation: excess mortality in leading causes of death in Spain. Prev Med. 2003;36(3):300-8.

4. Carstairs V, Morris R. Deprivation: explaining differences in mortality between Scotland and England and Wales. BMJ. 1989;299(6704):886-9.

5. Carstairs V. Deprivation indices: their interpretation and use in relation to health. J Epidemiol Community Health. 1995; 49(Suppl. 2):S3-8.

6. Challier B, Viel JF. Relevance and validity of a new French composite index to measure poverty on a geographical level. Rev Epidemiol Sante Publique. 2001;49(1): 41-50.

7. Havard S, Deguen S, Bodin J, Louis K, Laurent O, Bard D. A small-area index of socioeconomic deprivation to capture health inequalities in France. Soc Sci Med. 2008;67(12):2007-16.
8. Jarman B. Identification of underprivileged areas. Br Med J (Clin Res Ed). 1983; 286(6379):1705-9.

9. Jarman B, Townsend P, Carstairs V. Deprivation indices. BMJ. 1991;303(6801): 523.

10. Krieger N, Chen JT, Waterman PD, Soobader M, Subramanian SV, Carson R. Geocoding and monitoring of US socioeconomic inequalities in mortality and cancer incidence: does the choice of areabased measure and geographic level matter? Am J Epidemiol. 2002;156(5):471-82.

11. Krieger N, Chen JT, Waterman PD, Soobader MJ, Subramanian SV, Carson R. Choosing area based socioeconomic measures to monitor social inequalities in low birth weight and childhood lead poisoning: The Public Health Disparities Geocoding Project (US). J Epidemiol Community Health. 2003;57(3):186-99.

12. Kunst AE. Commentary: Using geographical data to monitor socioeconomic inequalities in mortality: experiences from Japanese studies. Int J Epidemiol. 2005; 34(1):110-2.

13. Noble M, McLennan D, Wilkinson K, Whitworth A, Barnes H. The English indices of deprivation 2007. London: Department for Communities and Local Government; 2008.

14. Salmond C, Crampton P, Sutton F. NZDep91: A New Zealand index of deprivation. Aust N Z J Public Health. 1998; 22(7):835-7.

15. Shaw M, Galobardes B, Lawlor DA, Lynch J, Wheeler B, Davey Smith G. The handbook of inequality and socioeconomic position. Bristol (UK): The Policy Press; 2007.

16. Tello JE, Jones J, Bonizzato P, Mazzi M, Amaddeo F, Tansella M. A census-based socio-economic status (SES) index as a tool to examine the relationship between mental health services use and deprivation. Soc Sci Med. 2005;61(10):2096-105.

17. Townsend P, Phillimore $P$, Beattie A. Health and deprivation: inequalities and the North. London (UK): Croom Helm; 1988.
18. Turrell G, Mathers C. Socioeconomic inequalities in all-cause and specific-cause mortality in Australia: 1985-1987 and 19951997. Int J Epidemiol. 2001;30:231-9.

19. Bell N, Hayes MV. The Vancouver Area Neighbourhood Deprivation Index (Vandix): a census-based tool for assessing small-area variations in health status. Can J Public Health. 2012;103 (Suppl. 2):S28-32.

20. Chateau D, Metge C, Prior H, Sooden R-A. Learning from the census: the Socioeconomic Factor Index (SEFI) and health outcomes in Manitoba. Can J Public Health. 2012;103(Suppl. 2):S23-7.

21. Frohlich N, Mustard C. A regional comparison of socioeconomic and health indices in a Canadian province. Soc Sci Med. 1996;42(9):1273-81.

22. Matheson FI, Dunn JR, Smith KLW, Moineddin R, Glazier RH. Development of the Canadian Marginalization Index: a new tool for the study of inequality. Can J Public Health. 2012;103(Suppl. 2):S12-6.

23. Pampalon R, Raymond G. A deprivation index for health and welfare planning in Quebec. Chronic Dis Can. 2000;21(3): 104-13.

24. Carr-Hill R, Chalmers-Dixon P. The Public Health Observatory handbook of health inequalities measurement. Oxford (UK): South East Public Health Observatory; 2005.

25. Gordon D. Census based deprivation indices: their weighting and validation. J Epidemiol Community Health. 1995 Dec;49(Suppl. 2):S39-44.

26. Gordon D. Area-based deprivation measures: a U.K. perspective. In: Kawachi I, Berkman LF, editors. Neighborhoods and health. Oxford: Oxford University Press; 2003. p. $179-210$.

27. Morris R, Carstairs V. Which deprivation? A comparison of selected deprivation indexes. J Public Health Med. 1991 Nov;13(4):318-26.

28. Statistics Canada. 2001 census dictionary [Internet]. Ottawa (ON): Statistics Canada; 2003 [cited 2012 Dec 13]. Available from: http://www12.statcan.ca/english/census01 /Products/Reference/dict/index.htm 
29. Porta M. A dictionary of epidemiology. 5th ed. Oxford University Press; 2008.

30. Townsend P. Deprivation. J Soc Pol. 1987; 16:125-46

31. Ministère de la santé et des services sociaux du Québec. Third national report on the health status of the population of Québec: rich in all our children: poverty and its impact on the health of children under 18. Québec (QC): MSSS; 2007.

32. Rey G, Jougla E, Fouillet A, Hemon D. Ecological association between a deprivation index and mortality in France over the period 1997-2001: variations with spatial scale, degree of urbanicity, age, gender and cause of death. BMC Public Health. 2009;9:33.

33. Salmond CE, Crampton P. Development of New Zealand's deprivation index (NZDep) and its uptake as a national policy tool. Can J Public Health. 2012;106(Suppl. 2):S7-11.

34. Congdon P. The epidemiology of suicide in London. J Royal Stat Soc Ser A. 1996;159:515-33.

35. Curtis S, Copeland A, Fagg J, Congdon P, Almog M, Fitzpatrick J. The ecological relationship between deprivation, social isolation and rates of hospital admission for acute psychiatric care: a comparison of London and New York City. Health Place. 2006;12(1):19-37.

36. Krieger $\mathrm{N}$, Zierler $\mathrm{S}$, Hogan JW, et al. Geocoding and measurement of neighborhood socioeconomic position: a U.S. perspective. In: Kawachi I, Berkman LF, editors. Neighborhoods and Health. Oxford (UK): Oxford University Press; 2003. p. $147-78$.

37. Schuurman N, Bell N, Dunn JR, Oliver L. Deprivation indices, population health and geography: an evaluation of the spatial effectiveness of indices at multiple scales. J Urban Health. 2007;84(4):591-603.

38. Berkman LF, Kawachi I, editors. Social epidemiology. Oxford (UK): Oxford University Press; 2000.

39. Hayes M, Foster LT, Foster HD. Community, environment and health: geographic perspectives. Victoria (BC): University of Victoria; 1992.
40. Insel PM, Moss RH. Health and the Social Environment. Toronto (ON): D.C. Health and Company; 1974.

41. Leclerc A, Fassin D, Grandjean H, Kaminski M, Lang T. Les inégalités sociales de santé. Paris (FR): Éditions La Découverte/Syros; 2000.

42. Pampalon R, Gamache P, Hamel D. The Québec index of material and social deprivation. Methodological follow-up, 1991 through 2006. Québec (QC): Institut national de santé publique du Québec; 2011.

43. Pampalon R, Hamel D, Gamache P. Residential mobility, deprivation and health in Québec. 14th International Medical Geography Symposium. Durham (UK); 2011.

44. Pampalon R, Raymond G. Indice de défavorisation matérielle et sociale: son application au secteur de la santé et du bienêtre. Santé, Société et Solidarité. 2003;(1): 191-208.

45. Ministère de l'emploi et de la solidarité sociale. Rapport statistique sur la clientèle des programmes d'assistance sociale. Québec (QC): Government of Quebec, MESS; 2012.

46. De Koninck M, Disant MJ, Pampalon R, Équipe de recherche sur les inégalités sociales de santé. Inégalités sociales de santé, influence des milieux de vie. Lien social et Politiques. 2006;55:125-36.

47. De Koninck M, Pampalon R. Living environments and health at a local scale: the case of three localities in the Québec City region. Can J Public Health. 2007; 98(S1):45-53.

48. Pampalon R, Hamel D, De Koninck M, Disant MJ. Perception of place and health: differences between neighbourhoods in the Québec City region. Soc Sci Med. 2007;65: 95-111.

49. Buckner JC. The development of an instrument to measure neighborhood cohesion. Am J Commun Psychol. 1988;16(6):771-91.
50. Statistique Canada. Canadian Community Health Survey [Internet]. Ottawa (ON): Statistics Canada; [modified 2012 Apr 23; cited 2013 Aug 8]. Available from: http:// www.hc-sc.gc.ca/fn-an/surveill/nutrition /commun/index-eng.php

51. Sherbourne C. The MOS social support survey. Soc Sci Med. 1991;32(6):705-14.

52. Philibert MD, Pampalon R, Hamel D, Daniel $M$. Interactions between neighborhood characteristics and individual functional status in relation to disability among Québec urbanites. Disabil Health J. Forthcoming 2013.

53. Carpiano RM. Toward a neighborhood resource-based theory of social capital for health: can Bourdieu and sociology help? Soc Sci Med. 2006;62(1):165-75.

54. Krieger N, Waterman PD, Chen JT, Soobader MJ, Subramanian SV. Monitoring socioeconomic inequalities in sexually transmitted infections, tuberculosis, and violence: geocoding and choice of areabased socioeconomic measures-the public health disparities geocoding project (US). Public Health Rep. 2003;118(3):240-60.

55. Pampalon R. Health expectancy and deprivation in Québec, 1996-1998. Québec: Institut national de santé publique du Québec; 2002.

56. Pampalon R, Hamel D, Gamache P. A comparison of individual and area-based socio-economic data for monitoring social inequalities in health. Health Rep. 2009;20(4):85-94.

57. Dupont MA, Pampalon R, Hamel D. Deprivation and cancer mortality among Quebec women and men, 1994-1998. Québec (QC): Institut national de santé publique du Québec; 2004.

58. Gagne M, Hamel D. Deprivation and unintentional injury hospitalization in Quebec children. Chronic Dis Can. 2009;29(2): 56-69.

59. Hamel D, Pampalon R. Trauma and deprivation in Québec. Québec (QC): Institut national de santé publique du Québec; 2002.

60. Martinez J, Pampalon R, Hamel D. Deprivation and stroke mortality in Quebec. Chronic Dis Can. 2003;24(2-3):57-64. 
61. Ministère de la santé et des services sociaux du Québec. Third national report on the health status of the population of Québec: rich in all our children: poverty and its impact on the health of children under 18. Québec (QC): MSSS; 2007.

62. Pampalon R, Hamel D, Gamache P. Les inégalités sociales de santé augmententelles au Québec? Québec (QC): Institut national de santé publique du Québec; 2008.

63. Pampalon R, Hamel D, Gamache P. Health inequalities, deprivation, immigration and aboriginality in Canada: a geographic perspective. Can J Public Health. 2010; 101(6):470-64.

64. Pampalon R, Hamel D, Gamache P. Portrait social du Québec. Données et analyses. Édition 2010. Québec (QC): Institut de la Statistique du Québec; 2010. Chapter 2. Les inégalités sociales de santé. Une réalité dont l'ampleur est sous-estimée. p. 51-64.

65. Pampalon R, Hamel D, Gamache P. Évolution de la mortalité prématurée au Québec selon la défavorisation matérielle et sociale. In: Frohlich K, De Koninck M, Bernard P, Demers A, editors. Les inégalités sociales de santé au Québec. Montréal (QC): Les Presses de l'Université de Montréal; 2008. p. 13-36.

66. Pampalon R, Hamel D, Gamache P. Recent changes in the geography of social disparities in premature mortality in Quebec. Soc Sci Med. 2008;67(8):1269-81.

67. Pampalon R, Hamel D, Gamache P. Health inequalities in urban and rural Canada: comparing inequalities in survival according to an individual and area-based deprivation index. Health Place. 2010; 16(2):416-20.

68. Pampalon R, Hamel D, Gamache P, Raymond G. A deprivation index for health planning in Canada. Chronic Dis Can. 2009;29(4):178-91.

69. Ross NA, Oliver LN, Villeneuve PJ. The contribution of neighbourhood material and social deprivation to survival: a 22 year follow-up of more than 500,000 Canadians. Int $\mathrm{J}$ Environ Res Public Health. 2013;10:1378-91.
70. Canadian Institute for Health Information. Reducing gaps in health: a focus on socioeconomic status in urban Canada. Ottawa (ON): CIHI; 2008.

71. Curtis S, Setia MS, Quesnel-Vallee A. Sociogeographic mobility and health status: a longitudinal analysis using the National Population Health Survey of Canada. Soc Sci Med. 2009;69(12):1845-53.

72. Schmitz N, Nitka D, Gariepy G, et al. Association between neighborhood-level deprivation and disability in a community sample of people with diabetes. Diabetes Care. 2009;32(11):1998-2004.

73. Aubé-Maurice J, Rochette L, Blais C. Relation entre la défavorisation et l'incidence de l'hypertension artérielle chez les individus de 20 ans et plus au Québec en 2006-2007. Québec (QC): Institut national de santé publique du Québec; 2010.

74. Ouhoummane N, Abdous B, Pampalon R, Hamel D, Poirier P. Impact of deprivation on post acute myocardial infarction mortality among men and women with diabetes in Québec, Canada. 2010 (unpublished).

75. Dubois L. Food, nutrition and population health: from scarcity to social inequalities. In: Heymann J, Hertzman C, Barer ML, Evans RG, editors. Healthier societies: from analysis to action. New York: Oxford University Press; 2006. p. 135-72.

76. Auger N, Park AL, Gamache P, Pampalon $\mathrm{R}$, Daniel M. Weighing the contributions of material and social area deprivation to preterm birth. Soc Sci Med. 2012;75(6): 1032-7.

77. Lasnier B, Leclerc BS, Hamel D. Les inégalités sociales de santé en matière de tabagisme et d'exposition à la fumée de tabac dans l'environnement au Québec. Québec (QC): Institut national de santé publique; 2012.

78. Blanchet C, Rochette L. Sécurité et insécurité alimentaire chez les Québécois: une analyse de la situation en lien avec leurs habitudes alimentaires. Québec (QC): Institut national de santé publique; 2011.

79. Philibert MD, Pampalon R, Hamel D, Thouez JP, Loiselle CG. Deprivation and utilization of health and social services in Québec: a local scale evaluation system. Soc Sci Med. 2007;64(8):1651-64.
80. Ministère de la santé et des services sociaux. Variations nationales de l'indice de défavorisation [Internet]. Québec (QC): Gouvernement du Québec, MSSS; 2008 [cited 2013 Aug 8]. Available from: http://www.msss.gouv.qc.ca/statistiques /atlas/atlas/index.php?id_carte $=11$

81. Davey-Smith G, Dorling D, Shaw M. Health inequalities in Britain: continuing increases up to the end of the 20th century. J Epidemiol Community Health. 2002;56:434-5.

82. Leclerc A, Chastang JF, Menvielle G, Luce D. Socioeconomic inequalities in premature mortality in France: have they widened in recent decades? Soc Sci Med. 2006;62(8): 2035-45.

83. Mackenbach JP, Bos V, Andersen O, et al. Widening socioeconomic inequalities in mortality in six Western European countries. Int J Epidemiol. 2003;32:830-7.

84. Singh GK, Siahpush M. Increasing inequalities in all-cause and cardiovascular mortality among US adults aged 25-64 years by area socioeconomic status, 1969-1998. Int J Epidemiol. 2002;31(3):600-13.

85. Pampalon R, Philibert M, Hamel D. Inégalités sociales et services de proximité au Québec: Développement d'un système d'évaluation issu d'une collaboration entre chercheurs et intervenants. Santé, Société et Solidarité. 2004;(2):73-88.

86. Ministère de la santé et des services sociaux du Québec. Nouveau mode d'allocation des ressources 2007-2008. Québec (QC): Gouvernement du Québec, MSSS; 2007.

87. Richard P, Drouin C. Consultation sur la participation régionale aux travaux d'inégalités sociales et de santé. Table nationale de surveillance, Forum de Concertation Interrégional en Surveillance; 2010.

88. Institut national de santé publique du Québec. Deprivation index [Internet]. Quebec (QC): Institute national de santé publique; [modified 2008 Nov 26; cited 2013 Aug 8]. Available from: http://www .inspq.qc.ca/santescope/liens.asp? $\mathrm{Lg}=$ en $\&$ NumVol $=$ undefined \&nav $=\mathrm{M} \& \operatorname{comp}=9$ 
89. Institut national de santé publique du Québec. Socio-economic comparisons [Internet]. Quebec (QC): Institute national de santé publique; [modified 2008 Aug 1; cited 2013 Aug 8]. Available from: http:// www.inspq.qc.ca/santescope/default.asp? $\mathrm{Lg}=\mathrm{en} \& \mathrm{NumVol}=5 \& \mathrm{nav}=\mathrm{M}$

90. Wilkins R, Tjepkema M, Mustard C, Choinière R. The Canadian census mortality follow-up study, 1991 through 2001. Health Rep. 2008;19(3):25-43.

91. Davey-Smith G, Hart C, Watt G, Hole D, Hawthorne V. Individual social class, areabased deprivation, cardiovascular disease risk factors, and mortality: the Renfrew and Paisley study. J Epidemiol Community Health. 1998;52:399-405.

92. Davey-Smith G, Hart C. Re: "Use of censusbased aggreagate variables to proxy for socioeconomic group: evidence from national samples". Am J Epidemiol. 1999;150(9):996-7.

93. Geronimus AT, Bound J. Use of censusbased aggregate variables to proxy for socioeconomic group: evidence from national samples. Am J Epidemiol. 1998; 148(5):475-86.

94. Krieger N. Overcoming the absence of socioeconomic data in medical records: validation and application of a censusbased methodology. Am J Public Health. 1992;82(5):703-10.

95. Krieger N, Gordon D. Re: "Use of censusbased aggregate variables to proxy for socioeconomic group: evidence from national samples". Am J Epidemiol. 1999; 150(8):892-6.

96. Rehkopf DH, Haughton LT, Chen JT, Waterman PD, Subramanian SV, Krieger N. Monitoring socioeconomic disparities in death: comparing individual-level education and area-based socioeconomic measures. Am J Public Health. 2006;96(12): 2135-8.

97. Subramanian SV, Chen JT, Rehkopf DH, Waterman PD, Krieger N. Comparing individual- and area-based socioeconomic measures for the surveillance of health disparities: A multilevel analysis of Massachusetts births, 1989-1991. Am J Epidemiol. 2006;164(9):823-34.
98. Bernard P, Charafeddine R, Frohlich KL, Daniel M, Kestens Y, Potvin L. Health inequalities and place: a theoretical conception of neighbourhood. Soc Sci Med. 2007;65(9):1839-52.

99. Cummins S, Curtis S, Diez-Roux AV, Macintyre S. Understanding and representing 'place' in health research: a relational approach. Soc Sci Med. 2007;65(9): 1825-38.

100.Frohlich KL, Dunn JR, McLaren L, et al. Understanding place and health: a heuristic for using administrative data. Health Place. 2007;13(2):299-309.

101.Krieger N. Epidemiology and the web of causation: has anyone seen the spider? Soc Sci Med. 1994;39(7):887-903.

102.Macintyre S, Ellaway A, Cummins S. Place effects on health: how can we conceptualise, operationalise and measure them? Soc Sci Med. 2002;55(1):125-39.

103. Northridge ME, Sclar ED, Biswas P. Sorting out the connections between the built environment and health: a conceptual framework for navigating pathways and planning healthy cities. J Urban Health. 2003;80(4):556-68. 